\title{
Crystal Structure of Fragments of Elastin Sequence (Boc-Ala-Pro-OBzl)
}

\author{
Beeranahally H. Doreswamy, ${ }^{*}$ Madegowda Mahendra, $*$ K. AbIraJ** D. Channegowda, ** \\ Sridhar M. AnANDalwar,* and Javaregowda S. PraSAD $* ;$ \\ *Department of Studies in Physics, University of Mysore, Manasagangotri, Mysore 570 006, India \\ **Department of Studies in Chemistry, University of Mysore, Manasagangotri, Mysore 570 006, India
}

\begin{abstract}
Fragments of elastin sequences of mammalian elastic protein elastin, like Ala-Pro, was synthesized and characterized by X-ray crystallography. The sequence $\left(\mathrm{C}_{20} \mathrm{H}_{28} \mathrm{~N}_{2} \mathrm{O}_{5}\right)$ crystallizes in the orthorhombic space group $P 22_{1} 2_{1}$ with the parameters $a=9.4240(9) \AA, b=11.1850(5) \AA, c=20.0800(19) \AA, V=2116.6(3) \AA^{3}, Z=4$. The final residual factor is 0.0612 .
\end{abstract}

(Received September 8, 2003; Accepted February 2, 2004; Published on Web March 18, 2004)

Elastic protein-based polymers have their origins in repeating sequences of the mammalin elastic protein. ${ }^{1}$ The parent polymers, (Val-Pro-Gly-Val-Gly) ${ }_{n}$ or poly(Val-Pro-Gly-ValGly), (Ala-Pro-Gly-Val-Gly-Val) $)_{n}$ or poly(Ala-Pro-Gly-ValGly-Val), (Val-Pro-Gly-Gly) ${ }_{n}$ or poly(Val-Pro-Gly-Gly) and (Val-Pro-Gly-Phe-Gly-Val-Gly-Ala-Gly) or poly(Val-Pro-GlyPhe-Gly-Val-Gly-Ala-Gly), derive from sequences that occur in all sequenced mammalian elastin protein. ${ }^{2}$ In the most striking

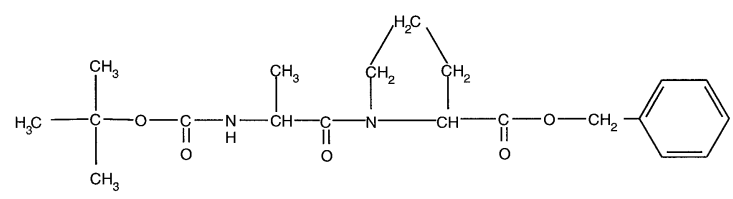

Fig. 1 Schematic diagram of the molecule.

Table 1 Crystallographic data

Formula: $\mathrm{C}_{20} \mathrm{H}_{28} \mathrm{~N}_{2} \mathrm{O}_{5}$

Formula weight $=376.44$

Crystal system: orthorhombic

Space group: $P 2_{1} 2_{1} 2_{1} \quad Z=4$

$a=9.4240(9) \AA$

$b=11.1850(5) \AA$

$c=20.0800(19) \AA$

$V=2116.6(3) \AA^{3}$

$D_{\mathrm{x}}=1.181 \mathrm{Mg} / \mathrm{m}^{3}$

$2 \theta_{\max }=45.96^{\circ}$ with Mo $\mathrm{K}_{\alpha}$

No. of reflections used $=2458[I>2 \sigma(I)]$

$R_{1}=0.0612$

$(\Delta / \sigma)_{\max }=0.001$

$(\Delta \rho)_{\max }=0.523 \mathrm{e}^{3}$

$(\Delta \rho)_{\min }=-0.602 \mathrm{e}^{3}$

Measurements: DipLabo Kappa(IP)

Program system: Denzo and Scalepak

Structure determination: SHELXS-97

Refinement: SHELXL-97

$\doteqdot$ To whom correspondence should be addressed.

E-mail:jsp@uomphysics.net. example, the sequence (Val-Pro-Gly-Val-Gly) ${ }_{n}$ occurs in bovine elastin with $n=11$ without a single substitution. ${ }^{1 \mathrm{a}, 3}$ Another repeat first found in procine elastin is (Val-Pro-Gly-Gly) ${ }_{n}$; this repeat has not been found to occur with $n>2$ without substitution. ${ }^{3}$ The monomers, oligomers and high polymers of these repeats have been synthesized and conformationally characterized. ${ }^{4}$ These polymers have a number of medical and non-medical applications. ${ }^{5}$ In view of the above, it is of interest to investigate the crystal structure of Boc-Ala-Pro-OBzl (Fig. $1)$.

To Boc-Ala-OH $(20 \mathrm{mmol})$, dissolved in acetonitrile $(35 \mathrm{~mL})$ and cooled to $0^{\circ} \mathrm{C}$, was added $N$-methylmorpholine (NMM) $(2.2$

Table 2 Atomic coordinates and equivalent thermal parameters

\begin{tabular}{lcccr}
\hline Atom & $x$ & $y$ & $z$ & \multicolumn{1}{c}{$U_{\text {eq }}$} \\
\hline O20 & $0.5919(3)$ & $0.8195(2)$ & $0.24178(11)$ & $0.0731(7)$ \\
O19 & $0.4733(3)$ & $0.8261(2)$ & $0.33798(11)$ & $0.0785(7)$ \\
N13 & $0.3711(3)$ & $0.7802(2)$ & $0.16792(13)$ & $0.0625(7)$ \\
N8 & $0.3880(3)$ & $0.5086(2)$ & $0: 07296(13)$ & $0.0712(8)$ \\
C18 & $0.4754(4)$ & $0.8208(3)$ & $0.27813(15)$ & $0.0621(8)$ \\
C11 & $0.4031(4)$ & $0.6641(3)$ & $0.15687(15)$ & $0.0641(8)$ \\
C17 & $0.3435(4)$ & $0.8198(3)$ & $0.23544(15)$ & $0.0642(8)$ \\
O5 & $0.2156(3)$ & $0.3796(2)$ & $0.05734(13)$ & $0.0855(8)$ \\
C6 & $0.2556(5)$ & $0.4961(3)$ & $0.05119(16)$ & $0.0728(9)$ \\
O12 & $0.4009(4)$ & $0.5921(2)$ & $0.20234(11)$ & $0.0847(9)$ \\
C22 & $0.8349(4)$ & $0.8202(3)$ & $0.22099(18)$ & $0.0732(9)$ \\
C21 & $0.7274(4)$ & $0.8298(4)$ & $0.27465(18)$ & $0.0783(10)$ \\
C10 & $0.4445(4)$ & $0.6274(3)$ & $0.08644(16)$ & $0.0703(10)$ \\
C14 & $0.3821(5)$ & $0.8792(3)$ & $0.12016(19)$ & $0.0787(10)$ \\
O7 & $0.1824(4)$ & $0.5742(3)$ & $0.02955(17)$ & $0.1016(10)$ \\
C27 & $0.9228(5)$ & $0.7205(4)$ & $0.2197(3)$ & $0.0957(13)$ \\
C15 & $0.3665(6)$ & $0.9891(3)$ & $0.1635(2)$ & $0.0970(14)$ \\
C16 & $0.2875(5)$ & $0.9467(4)$ & $0.2241(2)$ & $0.0891(13)$ \\
C9 & $0.6038(5)$ & $0.6272(4)$ & $0.0809(2)$ & $0.0921(12)$ \\
C3 & $0.0808(8)$ & $0.2071(5)$ & $0.0513(4)$ & $0.139(2)$ \\
C4 & $0.0752(5)$ & $0.3391(4)$ & $0.0363(2)$ & $0.1039(16)$ \\
C23 & $0.8423(6)$ & $0.8994(5)$ & $0.1710(2)$ & $0.1056(14)$ \\
C24 & $0.9342(7)$ & $0.8784(7)$ & $0.1155(3)$ & $0.1211(18)$ \\
C26 & $1.0131(6)$ & $0.7010(5)$ & $0.1665(3)$ & $0.1175(18)$ \\
C25 & $1.0124(6)$ & $0.7798(6)$ & $0.1150(3)$ & $0.1120(16)$ \\
C2 & $0.0595(10)$ & $0.3565(7)$ & $-0.0370(3)$ & $0.168(3)$ \\
C1 & $-0.0353(7)$ & $0.3984(8)$ & $0.0796(5)$ & $0.184(4)$ \\
& & & & \\
\hline
\end{tabular}

$\left[U_{\mathrm{eq}}=(1 / 3) \Sigma_{i} \Sigma_{j} U_{i j}\left(a_{i} * a_{j} *\right)\left(\boldsymbol{a}_{i} \cdot \boldsymbol{a}_{j}\right)\right]$ 
Table 3 Bond lengths $(\AA)$

\begin{tabular}{llll}
\hline Atom & Length & Atom & Length \\
\hline O20-C18 & $1.318(4)$ & C6-O7 & $1.195(5)$ \\
O20-C21 & $1.442(5)$ & C22-C23 & $1.341(6)$ \\
O19-C18 & $1.203(4)$ & C22-C27 & $1.389(6)$ \\
N13-C11 & $1.351(4)$ & C22-C21 & $1.483(5)$ \\
N13-C17 & $1.450(4)$ & C10-C9 & $1.505(6)$ \\
N13-C14 & $1.469(4)$ & C14-C15 & $1.513(5)$ \\
N8-C6 & $1.330(5)$ & C27-C26 & $1.384(7)$ \\
N8-C10 & $1.457(5)$ & C15-C16 & $1.503(7)$ \\
C18-C17 & $1.510(5)$ & & \\
C11-O12 & $1.218(4)$ & & \\
C11-C10 & $1.523(4)$ & & \\
C17-C16 & $1.531(5)$ & & \\
O5-C6 & $1.362(5)$ & & \\
O5-C4 & $1.462(5)$ & & \\
\hline
\end{tabular}

$\mathrm{mL}, 20 \mathrm{mmol})$. The solution was cooled to $-15^{\circ} \mathrm{C} \pm 1{ }^{\circ} \mathrm{C}$ and isobutylchloroformate $(2.6 \mathrm{~mL}, 20 \mathrm{mmol})$ was added under stirring while maintaining the temperature at $-15^{\circ} \mathrm{C}$. After stirring the reaction mixture for $10 \mathrm{~min}$ at this temperature, a pre-cooled solution of HOBt (3.1 g. $20 \mathrm{mmol})$ in DMF (30 mL) was added. The reaction mixture was stirred for an additional $10 \mathrm{~min}$ and a pre-cooled solution of $\mathrm{HCl} \cdot \mathrm{H}-\mathrm{Pro}-\mathrm{OBzl}(4.85 \mathrm{~g}$, $20 \mathrm{mmol})$ and NMM (2.2 mL, $20 \mathrm{mmol})$ in DMF (40 mL) was added slowly. After $20 \mathrm{~min}$, the $\mathrm{pH}$ of the solution was adjusted to eight by the addition of NMM, and the reaction mixture was stirred over night at room temperature. Acetonitrile was removed under reduced pressure, and the residual solution was poured into about $400 \mathrm{~mL}$ of an ice-cooled $90 \%$ saturated $\mathrm{KHCO}_{3}$ solution, and stirred for $30 \mathrm{~min}$. The precipitate was filtered, washed with water, cold $1 \mathrm{M} \mathrm{HCl}$, water and then dried. The crude peptide was recrystallized from ether and petroleum ether to obtain $6.87 \mathrm{~g}$ of Boc-AP-OBzl (yield, 91.2\%). $R_{f}^{1}, 0.50 ; R_{f}^{2}, 0.63 . \quad[\alpha]_{\mathrm{D}}{ }^{25}(\mathrm{C}, 1 ; \mathrm{MeOH})-13.4$, m.p. $67^{\circ} \mathrm{C}$.

Single crystal of $0.3 \times 0.25 \times 0.2 \mathrm{~mm}$ was chosen for X-ray diffraction studies. The measurements were made on a DIPLabo Imaging Plate system with graphite-monochromated radiation $\left(\mathrm{Mo} \mathrm{K}_{\alpha}\right)$. The structure was solved and refined using the maXus ${ }^{6}$ program. All the non-hydrogen atoms were revealed in the first map. A full-matrix least-squares refinement based on 2458 observed reflections $(I>2 \sigma(I))$ with isotropic temperature factors for all the atoms converged to a residual of $R=0.1397$. A refinement of non-hydrogen atoms with anisotropic thermal parameters was started at this stage. After eight cycles of refinement, the residuals saturated at $R=0.0612$. The hydrogen atoms were placed at calculated positions, and included using the riding atom model. Table 1 gives the details of the crystal and experimental data. Absolute configuration has been assigned by reference to an unchanging chiral centre in the synthetic procedure.

The final positional coordinates along with equivalent isotropic temperature factors for all of the non-hydrogen atoms are given in Table 2. Tables 3 gives the bond distances of the non-hydrogen atoms, respectively. The bond lengths and angles are in good agreement with their standard values. Figure 2 represents an ORTEP diagram of the molecule with thermal ellipsoids at $50 \%$ probability. The packing diagram of the molecule shows stacking when viewed along the $a$ axis. The dihedral angle between the plane of atoms, $\mathrm{C} 22$ to $\mathrm{C} 27$, and that of atoms $\mathrm{N} 13$ to $\mathrm{C} 17$ is $27.1(3)^{\circ}$, with a maximum deviation of $0.016(6) \AA$ for $\mathrm{C} 26,0.192(5) \AA$ for $\mathrm{C} 15$ and $0.161(4) \AA$ for $\mathrm{C} 17$ respectively. The structure has both intra and intermolecular

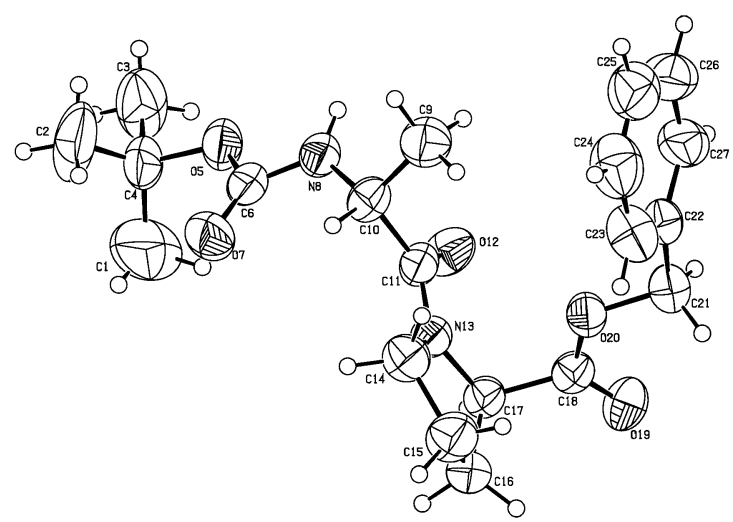

Fig. 2 ORTEP diagram of the molecule at the $50 \%$ probability.

hydrogen bonds, which are as follows: C2-H20A $\cdots \mathrm{O} 7$

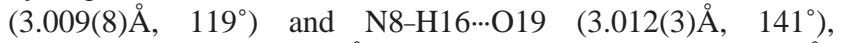

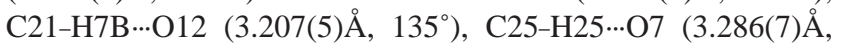
$\left.134^{\circ}\right)$ with symmetry codes $(1-x,-1 / 2+y, 1 / 2-z),(1-x, 1 / 2$ $+y, 1 / 2-z),(1+x, y, z)$ respectively.

The bond lengths and angles of the peptide link are in conformity with those of similar molecules. The peptide bond between $\mathrm{C} 11-\mathrm{N} 13$ is $1.351(4) \AA$ and between $\mathrm{C} 11-\mathrm{O} 12$ is $1.218(4) \AA$. The values are as expected in peptide linkages. The conformation of the dipeptide is identified as follows: the rotations about $\mathrm{C} 10-\mathrm{C} 11, \mathrm{~N} 8-\mathrm{C} 10$ and $\mathrm{C} 11-\mathrm{N} 13$ are, respectively, $\psi=-143.7(3)^{\circ}, \phi=85.2(4)^{\circ}$ and $\omega=-174.6(3)^{\circ}$.

\section{Acknowledgements}

The authors would like to express their thanks to DST, Government of India for financial assistance under the project SP/I2/FOO/93.

\section{References}

1. (a) L. Sandberg, C. Leslie, V. Trres, A. Smith, and D. Smith, Pathol. Biol., 1985, 33 266. (b) H. Yeh, N. Ornstein-Goldstein, Z. Indik, P. Shepperd, N. Anderson, J. Rosenbloom, G. Cicila, K. Yoon, and J. C. Rosenbloom, Collagen Rel. Res., 1987 7, 235.

2. Z. Indik, H. Yeh, N. Ornstein-Goldstein, P. Sheppard, N. Anderson, J. rosenbloom, L. Peltonen, and J. C. Rosenbloom, Proc. Natl. Acad. Sci., USA, 1987 84, 5680.

3. L. B. Sandberg, N. T. Soskel, and J. B. Leslie, N. Engl. J.Med., 1981 304, 566.

4. D. C. Gowda, T. M. Parker, R. D. Harris, and D. W. Urry, "Synthesis, characterizations and Medical applications of bioelastic materials", in "Peptides", ed. C. Basava and G. M. Anantharamaiah, Birkhauser, Boston, 1994, 81 - 111.

5. D. W. Urry, A. Nicol, D. C. Gowda, L. D. Hoban, A. McKee, T. Williams, D. B. Olsen, and B. A. Cox, in "Medical applications of bioelastic materials", C. G. Gebelein, Technomic Publishing, Atlanta 1993, 82 - 103.

6. S. Mackay, C. J. Gilmore, C. Edwards, N. Stewart, and K. Shankland, 1999. maXus Computer Program for the Solution and Refinement of Crystal Structures. Bruker Nonius, The Netherlands, MacScience, Japan and The University of Glasgow. 